\title{
Ensayo
}

\section{Ideas acerca de un nuevo concepto de cultura}

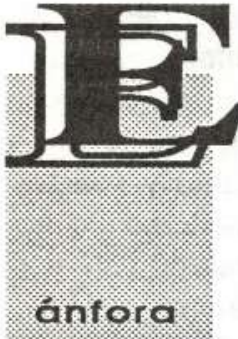

1 concepto de cultura necesita redefinirse desde una perspectiva más amplia. Será así uno de los conceptos más ricos para la intelección del mundo y de las relaciones que con él tiene el hombre. Presentamos aquí una primera aproximación filosófica a lareflexión sobre el papel consolidador de la cultura como plexo de fenómenos del mundo simbólico.

Cultura en su sentido más originario es la conciencia de la separación del hombre con respecto a la naturaleza.Pero separarse no es abandonar las relaciones que se dan en densas tramas y se estructuran de manera dinámica entre el mundo real y el mundo simbólico.

La explicación histórica del concepto de cultura se ha dado por la construcción de horizontes donde el arte, la ciencia, la religión, la tecnología y en general, la cotidianidad, se presentan como mundos alternos de carácter simbólico, que dialogan con la naturaleza, que surgen a partir de la relación fenomenológica entre los hombres, las comunidades, las sociedades. Este movimiento no se da exento de crisis o movimientos de valores y antivalores, sistemas y antisistemas, culturas oficiales y «contraculturas».

\section{Cultura y región}

El manejo histórico del mundo simbólico, la interpretación del horizonte cultural de una re-
Jorge Echeverri González

Profesor U. Autónoma

Patricia Noguera de Echeverri

Profesora As. U. Nacional

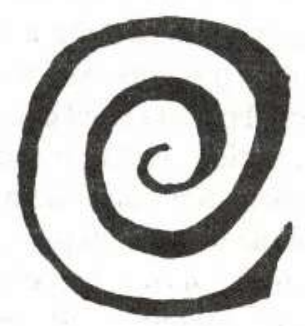

gión, amerita una construcción discursiva de las imágenes que se expresan de manera inmediata, pero que es necesario interpretarlas y comprenderlas teóricamente para leer desde dicho sentido las identificaciones y diferenciaciones. Como el contex to no es lineal sino complejo, utilizamos el concepto de horizonte cultural. La trama de fenómenos de orden significativo que intervienen en la construcción de este horizonte o contexto cultural, lo llamamos plexo de sentido.

El plexo cultural de nuestra región tiene un movimiento que va de lo regional a lo universal y regresa a lo regional. La mirada debe dirigirse a la multidireccionalidad de las racionalidades que se han cruzado en las construcciones sociales, políticas y económicas para encontrar los símbolos y elementos significacionales propios de los niveles inconcientes de los imaginarios colectivos. El 
sondeo crítico a partir de la diversidad de las regiones, nos permite integrar lo que se ha mirado separado y a su vez separar lo que por determinaciones de la cultura oficial se ha homogeneizado.

Este movimiento de la reflexión implica mayor comprensión de la identidad y de la diferencia de los diversos tejidos del plexo cultural de nuestras regiones, para que al mirar el horizonte desde la perspectiva regional no se pierda su sentido holístico.

\section{El concepto de cultura en la modernidad.}

En la modernidad el concepto de cultura parte del paso tortuoso, trágico y a la vez optimista, del mundo sagrado al mundo profano. Al convertirse la razón humana en el centro de toda la acción, la cultura se determina de manera problemática. El primer nivel de lectura del plexo cultural se realiza dentro del proceso genético-histórico. Allí se interrelacionan los fenómenos políticos, económicos, sociales y simbólicos (arte, lúdica, poética, lenguaje). Desde este nivel se interpretan los fenómenos de la regionalización, las actividades económicas y las direcciones que va tomando la racionalidad en sus formas de modernización y su explicitación en la constitución de los asentamientos, para el desarrollo de estas racionalidades. A partir de esta interpretación se van comprendiendo los diversos modelos que han penetrado en nuestras regiones y las propuestas propias: su lucha, su fracaso o su victoria, dinámica que genera la identidad y la diversidad. Los grupos humanos se van apropiando de los espacios físico sociales y a partir de la dinámica cotidiana construyen colectivamente los imaginarios que los aglutinan.

El segundo nivel de lectura es el histórico hermenéutico, que nos permitareconstruir los «textos» simbólico naturales. Una lectura crítica del mundo simbólico regional, dentro del contexto nacional, permite encontrar otros niveles cada vez más intangibles. La interpretación de lo intangible nos permite entrar, desde nuestra racionalidad discursiva, en el mundo ético, estético y lúdico, en el umbral de lo sagrado de la cultura.

El desgarramiento entre la naturaleza y el hombre, propio de la cultura moderna, partió desde la consolidación de la razón subjetiva. Descartes conduce a la escisión del yo: el yo pienso (yo intelectual, base de todo conocimiento, sujeto ordenador del mundo por medio de la lógica) y el yo siento (yo natural, base de sentimientos, de sensaciones y voliciones). El hombre moderno ya no pertenece a la naturaleza. Está por encima de ella, la domina, calcula, ordena. La expresa en términos de fórmula y de estadísticas. La razón muestra su superioridad frente a la naturaleza, aun en el arte, considerando lo bello sólo como categoría del arte, o más bien, de la filosofía del arte, y no de la naturaleza. ${ }^{1}$

Cultura, entonces, se entiende como la más depurada expresión del espíritu (como opuesto a materia, forma sensible). La relación inmediata con la naturaleza no es aceptada como «culta». Otras relaciones más mediatizadas, donde hay un desarrollo tecnológico, tampoco se aceptan como cultura. Solamente caben dentro del concepto las realizaciones del espíritu, como las artes, las ciencias, las religiones, las filosofías.

Desde otra perspectiva de la modernidad, la interpretación maniquea derivada de la propuesta de análisis marxista, condujo a comprender el mundo de la vida dividido, donde la infraestructura, base de la vida social (relaciones económicas y sociales de producción) sostiene la superestructura (mundo simbólico). Esta interpretación le negó a la cultura la posibilidad de entenderse desde sí misma. Incluso el concepto de naturaleza se redu- 
jo, pues no podía mirársela con ojos «románticos» ni «idealistas».

Así como arte y naturaleza, política y ciencia, ética y vida cotidiana eran escindidos por las diversas direccionalidades de la razón, la idea de cultura se manifestaba como un hecho aparte de los demás hechos históricos.

A partir de los esfuerzos del mismo hombre occidental, dividido interior y exteriormente por sus propios racionalismos políticos, económicos, científicos y estéticos, se inicia una crítica radical desde la razón misma, a tales reduccionismos. Dicha crítica se ha encaminado a elucidar el origen de la reducción y por tanto la revisión esencial recae en el concepto de cultura en general y de cultura moderna en particular.

\section{La cultura como concepto integrador.}

La reflexión filosófica debe ocuparse en la actualidad por la construcción de un nuevo paradigma que permita la integración, la reconciliación crítica y compleja de lo escindido. Por ello, si la cultura como concepto se encuentra separada de la vida cotidiana, así como la ética está lejos de las acciones diarias del hombre común, y la política pareciera ser un sistema de tecnologías burocráticas, sólo conocido por un reducido número de personas, se hace necesaria la construcción de nuevos paradigmas conceptuales, que integren la cultura a la vida cotidiana, la ética a las acciones diarias de los hombres y las instituciones y la política a las acciones de las comunidades en sus relaciones participativas y decisorias con el Estado.

La cultura es ahora un concepto integrador en construcción, que expresa la cotidianidad de los pueblos, su mundo simbólico, ya sea que se manifieste en arte, tecnologías, lenguaje, costumbres, instituciones, política o ética, como formas de expresión general de la voluntad y el inconsciente colectivos. La cultura es la manifestación consciente de un mundo alternativo al mundo natural por medio de la cual se mediatizan las

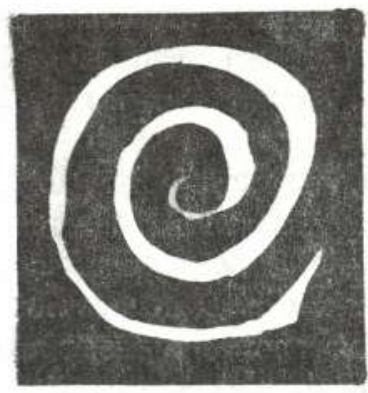

relaciones de la humanidad con la naturaleza y con ella misma. Desde la misma razón, desde la reflexión filosófica, podemos construir nuestro concepto de cultura y en general los nuevos paradigmas que permitan integrar la identidad con la diferencia.

En las regiones debemos leer imágenes y referentes simbólicos a partir de su génesis histórica. El hombre colombiano desde su origen se enfrenta a la situación de desarraigo, característica de todos los procesos de colonización. El colono busca tierra porque está sin tierra. Su objetivo es encontrar un espacio, una región donde pueda realizar su historia y construír su identidad.

Tomemos un ejemplo: la arriería antioqueña. Este primer fenómeno de sentido permite establecer en la definición de «lo caldense» un elemento identificatorio. El relativo aislamiento de Caldas permite también ciertas condiciones de definición de esa identidad que se desmembra paulatinamente de «lo antioqueño», pues va delimitando no solo fronteras físicas fuertes, sino también fronteras en el sentido epistemológico: localdense 
se estructura con base en elementos originales comunes dados por la «antioqueñidad», pero que poco a poco se van diferenciando, gracias a los elementos geográficos y a las situaciones históricas peculiares de la región. También por las determinantes de orden económico y social que van construyendo su identidad regional: lo caldense como frontera, elemento rico de análisis.

Todo el proceso está transido por el concepto de modemidad y en el contexto de un movimiento más amplio. Importamos modelos extraños para construír la ilusión de nación, de individuo, democracia, libertad. Arquitectura, artes plásticas, música, literatura, vida cotidiana de las clases adineradas, formas de educación, la política, la ciencia y la tecnología obedecen a modelos importados que se traducen en la idea de desarrollo y modernización. Se instala el imperio normativo de la razón, en un mundo cuya esencia es el mito. Se sustenta así la contradicción que se da entre fenómenos tan extraordinarios como la literatura o las artes plásticas colombianas y tan hórridos como la violencia en todas sus manifestaciones (política, social, psicológica) generalmente rodeada de anonimato e impunidad.

Con el imperio normativo de la razón se da, entonces, nacimiento a la separación entre fe y saber, mito y verdad, sueño y realidad. La conciencia de la separación entre mundo sagrado y mundo profano es también la conciencia de la ausencia de lo sagrado, es decir, de lo inexplicable desde la lógica.

La modernidad en Colombia sólo existe como perspectiva desde otras perspectivas. La opción de centrar el sentido del mundo sólo en la razón subjetiva, es una opción que debe debatirse, pues la experiencia de Europa nos muestra los límites de la misma razón. Negar las influencias, nexos y presencias sería una actitud ingenua. Pero el paradigma de la cultura moderna precisa mayor reflexión, en particular en sus manifestaciones institucionales y simbólicas que determinan la vida cotidiana de las regiones. La lectura de imágenes nos debe llevar a la comprensión de la diversidad real que permanece presente en sus imaginarios colectivos. A esa diversidad que podemos llamarla "contracultural» por cuanto de raíz se diferencia de la cultura oficial, debe dirigirse el interés de nuestra mirada.

En Colombia la presencia de lo sagrado es parte esencial de la cotidianidad. Nuestra cultura -no la oficial- es una perspectiva de perspectivas que se manifiesta en todos los ámbitos. No hemos renunciado a nuestro derecho a lo sagrado. No hemos renunciado a nuestro yo siento aunque tampoco hemos llegado al yo pienso en el estricto sentido filosófico.

La integralidad de lo sagrado y lo profano está en la construcción de un nuevo concepto de cultura que descentre la razón de la subjetividad y la coloque en la interacción comunitaria. Es necesario además, reconocer de manera epistemológica la dependencia absoluta del hombre con respecto de naturaleza, cambiando la idea de que es ella la que depende del hombre. La naturaleza como universo infinito en expansión, donde la razón también está presente.

Es necesaria la reflexión sobre la cultura y la propuesta de una eticidad nueva basada en la responsabilidad, en un cambio de paradigma que permita el reconocimiento de la diferencia y los límites. Realizarlo significa mirar desde dentro los procesos homogeneizantes del modernismo en Colombia y construír participativamente alternativas culturales críticas.

${ }^{1}$ HEGEL, F. Estética. De lo bello y sus formas. Madrid, Espasa-Calpe, 1977, Sa edición. 